\title{
A Study on the Nonmetallic Inclusion Motions in a Swirling Flow Submerged Entry Nozzle in a New Cylindrical Tundish Design
}

\author{
PEIYUAN NI, MIKAEL ERSSON, LAGE TORD INGEMAR JONSSON, \\ and PÄR GÖRAN JÖNSSON
}

Different sizes and shapes of nonmetallic inclusions in a swirling flow submerged entry nozzle (SEN) placed in a new tundish design were investigated by using a Lagrangian particle tracking scheme. The results show that inclusions in the current cylindrical tundish have difficulties remaining in the top tundish region, since a strong rotational steel flow exists in this region. This high rotational flow of $0.7 \mathrm{~m} / \mathrm{s}$ provides the required momentum for the formation of a strong swirling flow inside the SEN. The results show that inclusions larger than $40 \mu \mathrm{m}$ were found to deposit to a smaller extent on the SEN wall compared to smaller inclusions. The reason is that these large inclusions have Separation number values larger than 1. Thus, the swirling flow causes these large size inclusions to move toward the SEN center. For the nonspherical inclusions, large size inclusions were found to be deposited on the SEN wall to a larger extent, compared to spherical inclusions. More specifically, the difference of the deposited inclusion number is around 27 pct. Overall, it was found that the swirling flow contains three regions, namely, the isotropic core region, the anisotropic turbulence region and the near-wall region. Therefore, anisotropic turbulent fluctuations should be taken into account when the inclusion motion was tracked in this complex flow. In addition, many inclusions were found to deposit at the SEN inlet region. The plotted velocity distribution shows that the inlet flow is very chaotic. A high turbulent kinetic energy value of around $0.08 \mathrm{~m}^{2} / \mathrm{s}^{2}$ exists in this region, and a recirculating flow was also found here. These flow characteristics are harmful since they increase the inclusion transport toward the wall. Therefore, a new design of the SEN inlet should be developed in the future, with the aim to modify the inlet flow so that the inclusion deposition is reduced.

https://doi.org/10.1007/s11663-017-1162-y

(c) The Author(s) 2017. This article is an open access publication

\section{INTRODUCTION}

NonMeTALLIC inclusions are of highest importance during steel production. This is due to the fact that they not only can affect the steel product quality in a negative manner but can also cause an interruption of the continuous casting process by clogging the tundish submerged entry nozzle (SEN). To summarize,

PEIYUAN NI is with the Key Laboratory of Ecological Metallurgy of Multi-metal Intergrown Ores of Education Ministry, School of Metallurgy, Northeastern University, 110819 Shenyang, China and also with the Department of Materials Science and Engineering, KTH Royal Institute of Technology, 10044 Stockholm, Sweden. Contact email: peiyuann@kth.se MIKAEL ERSSON, LAGE TORD INGEMAR JONSSON, and PÄR GÖRAN JÖNSSON are with the Department of Materials Science and Engineering, KTH Royal Institute of Technology.

Manuscript submitted July 21, 2017

Article published online December 29, 2017. inclusions induce product or production problems, which are closely related to the inclusion transport in steel flows during the continuous casting process. Therefore, the understanding of inclusion behaviors in steel flows is important to optimize the production process and to improve the product quality.

In the tundish and mold, steelmakers have the last chance to remove nonmetallic inclusions in order to make steel clean. The removal of inclusions in the tundish can reduce the number concentration of inclusions in the molten steel, which is expected to reduce the clogging rate in the tundish SEN. In the past, a large number of numerical simulation studies have investigated the behaviors of inclusions during the steel continuous casting process. ${ }^{[1-25]}$ For the inclusion motion in tundish, studies have been carried out to investigate the inclusion removal under the effects of various factors such as flow control devices, tundish geometries, gas bubbling rates, and inclusion sizes. ${ }^{[1-8]}$ After inclusions move from the tundish into the SEN, 
their deposition on the SEN wall can lead to nozzle clogging. In order to understand the deposition location and mechanism, computational fluid dynamics (CFD) studies have been carried out to investigate the inclusion transport in turbulent steel flows and its deposition on the SEN walls. ${ }^{[9-17]}$

Deposition rates of inclusions on the SEN wall were predicted by using an Eulerian deposition model, which considered the transport of inclusions in the turbulent flow boundary layer as well as the turbophoresis effect. ${ }^{[16,17]}$ Finally, inclusions move into the mold accompanying steel flows, where the solidification of molten steel happens. The concerns about inclusions in molds include its removal to the top mold slag and its capture by the solidifying front. These concerns have been investigated in many CFD studies focusing on SEN port designs, SEN submerged depths, argon injection, electromagnetic braking, and so on. ${ }^{[18-25]}$ Among them, the particle-capture model developed by Thomas et al. ${ }^{[25]}$ gives a good contribution to describe the particle capture behavior at the solidifying front, since it represents a good physical framework by considering the local force balances.

In recent years, the use of a swirling flow or a rotational flow during steel castings has received a lot of attention. Two methods to realize a swirling flow or rotational flow during the steel casting have been intensively studied, namely, the swirling flow SEN method $^{[26-34]}$ and the mold-electromagnetic stirring (MEMS) method. ${ }^{[35-38]}$ When using a swirling flow SEN, the penetration depth of the SEN outlet flow in mold was found to decrease. ${ }^{[28]}$ The stability of the steel flow in the mold was enhanced and the defects on the slab surface were effectively reduced. ${ }^{[31]}$ Furthermore, the swirling flow in the SEN was found to effectively reduce the clogging tendency of the SEN port. ${ }^{[31]}$ This is due to the fact that the nozzle port flow becomes homogenous and stable when a swirling flow exists in the SEN. In addition, a swirling flow produced by the rotary MEMS method in an industry application was found to effectively reduce the central cracks, central porosities, and shrinkages. ${ }^{[36]}$ Therefore, the use of a swirling flow or a rotational flow during metal castings is becoming an important way to produce high-quality steels. However, previous studies ${ }^{[26-38]}$ of swirling flows during steel castings mainly focused only on the influence on the steel flow itself. Furthermore, previous studies ${ }^{[1-25]}$ focusing on the inclusion behavior in steel flows have mostly been carried out for conventional continuous casting processes, where no rotational steel flow phenomena exist in the horizontal cross sections of the SEN or the mold. In a swirling flow, the motions of the light nonmetallic inclusions are expected to be different from those in a conventional casting flow. This is due to the centripetal separation effect, which causes light inclusions, with a density smaller than molten steel, to move toward the swirling flow center. This may change the transport and deposition behavior of nonmetallic inclusions.

As mentioned earlier, the inclusion motion is important for both the steel quality and the steel production process. Therefore, it is interesting and meaningful to investigate the influence of a swirling steel flow on the inclusion behaviors during casting operations. Previous studies on the behaviors of nonmetallic inclusions in swirling steel flows are limited. Yang et al. ${ }^{[32,33]}$ investigated the nonmetallic inclusion motion in a swirling flow, which was obtained by applying electromagnetic stirring outside the SEN. Ni et al. ${ }^{[3]}$ investigated the behaviors of $\mathrm{Al}_{2} \mathrm{O}_{3}$ and $\mathrm{Ce}_{2} \mathrm{O}_{3}$ inclusions in a swirling flow SEN obtained from a new tundish design. It was found that large size light nonmetallic inclusions move toward the swirling flow center, due to the centripetal separation effect. ${ }^{[34]}$ Hou et al. ${ }^{[39]}$ investigated the inclusion removal in a swirling flow chamber, which was installed at the tundish inlet region. It was found that this design is suitable to use for the removal of $20-\mu \mathrm{m}$ inclusions but not large size inclusions, compared to a conventional tundish. ${ }^{[39]}$ However, these simulation studies were carried out using swirling flow fields, which were solved by using the $k-\varepsilon$ type turbulence model in combination with a standard wall function. ${ }^{[32-34,39]}$ Thereafter, a Lagrangian particle tracking scheme was used to describe the inclusion motion in the solved flow fields. Therefore, the isotropic turbulent fluctuations were assumed and the turbulent boundary layer was not resolved. However, in a swirling flow, a large velocity gradient ranging from the swirling flow center to the wall normally exists in the radial direction. Anisotropic fluctuations may exist in such a flow situation. This is especially true in the turbulent boundary layer. Furthermore, turbophoresis has been found to be of importance when considering the particle transport in turbulent boundary layer. ${ }^{[16,17]}$ However, these aspects have been ignored in previous studies. ${ }^{[32-34,39]}$ In the absence of resolving the turbulence boundary layer, inclusions may simply fly to the wall once they reach the wall-adjacent grid cell. Therefore, this cannot give a good prediction on the inclusion transport toward a wall when particle depositions in turbulent flows occur. This has been confirmed by results in the literature. ${ }^{[40]}$ In addition, both the flow field and the inclusion motion have previously not been validated by experiments. ${ }^{[32-34]}$ Also, a recent study shows that the $k-\varepsilon$ type turbulent models sometimes underpredict the swirling flow intensity. ${ }^{[41]}$ Therefore, studies are still required to give a good prediction on the transport of inclusions, toward the swirling flow center and toward the wall, in a swirling flow or a rotational steel flow.

In this article, the behaviors of nonmetallic inclusions in the swirling steel flow in a new cylindrical tundish design were investigated based on both numerical simulations and water model experiments. The steel flow field has been solved by using a Reynolds stress turbulent model (RSM), combined with a Stress-Omega submodel, to account for the possible anisotropic fluctuations in a swirling flow. Furthermore, the numerical model was validated by particle image velocimetry measurements in water model experiments. ${ }^{[42]}$ In addition, the turbulent boundary layer was also resolved. Specifically, the $y^{+}$value of the first grid layer was smaller than 1, and 21 layers of grid cells were used at the near-wall region to account for the turbophoresis 
effect for particle transport in the turbulent boundary layer. This should improve the accuracy of the predictions of the particle transport toward a wall compared to the previously presented results. ${ }^{[32-34]}$ Different shapes and sizes of $\mathrm{Al}_{2} \mathrm{O}_{3}$ inclusions were tracked using a Lagrangian scheme that accounted for the inertial force, drag force, gravity and buoyancy, lift force, pressure gradient force, and virtual mass force acting on each individual inclusion. Also, a statistical analysis was carried out to investigate the number of inclusions, released from the location close to the SEN inlet, that touch the SEN wall in different regions along the vertical direction of the SEN. In addition, the separation phenomena, due to the centripetal effect, of the light nonmetallic inclusions in the swirling steel flow were studied. Furthermore, a dimensionless number, the Separation number, was for the first time proposed in this article. This number can be used to define the possibility of different inclusions to be separated in a swirling flow.

\section{MODEL DESCRIPTION}

The three-dimensional mathematical model of the new cylindrical tundish is made in a Cartesian coordinate system. The steel flow field in the new tundish has previously been solved by using the $\mathrm{RSM}^{[43-45]}$ combined with the Stress-Omega ${ }^{[45,46]}$ submodel. Furthermore, the predictions have been validated by water model experiments. ${ }^{[42]}$ The inlet steel flow rate is $5.0 \mathrm{~m}^{3} / \mathrm{h}$. The steel density and its molecular viscosity are $7000 \mathrm{~kg} / \mathrm{m}^{3}$ and $0.0064 \mathrm{~kg} /(\mathrm{m}$ $\mathrm{s})$, respectively. Molten steel flows into the cylindrical tundish from its tangential inlet. This leads to a rotational steel flow inside the cylindrical tundish. After the rotational steel flow moves into the SEN, a swirling flow can be produced due to the rotational flow potential. In the current article, the previously solved steel flow field was used to study the behaviors of inclusions in the tundish and SEN.

The model geometry, the injection locations of inclusions, and the divided SEN wall regions are shown in Figure 1. The other model information can be found in the literature ${ }^{[42]}$ and is not repeated here. The inclusion tracking was done using the discrete phase model, which is available in the commercial software ANSYS FLUENT 17.0 ${ }^{\circledR}$. The density of the $\mathrm{Al}_{2} \mathrm{O}_{3}$ inclusions was assumed to be $3500 \mathrm{~kg} / \mathrm{m}^{3}$, based on the data from Reference 47.

\section{A. Inclusion Tracking Assumption and Boundary Condition}

(1) Inclusions escaped from the domain when they exited from the SEN outlet.

(2) Inclusions were assumed to stick on the SEN wall once they touched it; a "reflect" boundary condition was used for the other tundish walls.

(3) Interactions between inclusions were not considered.

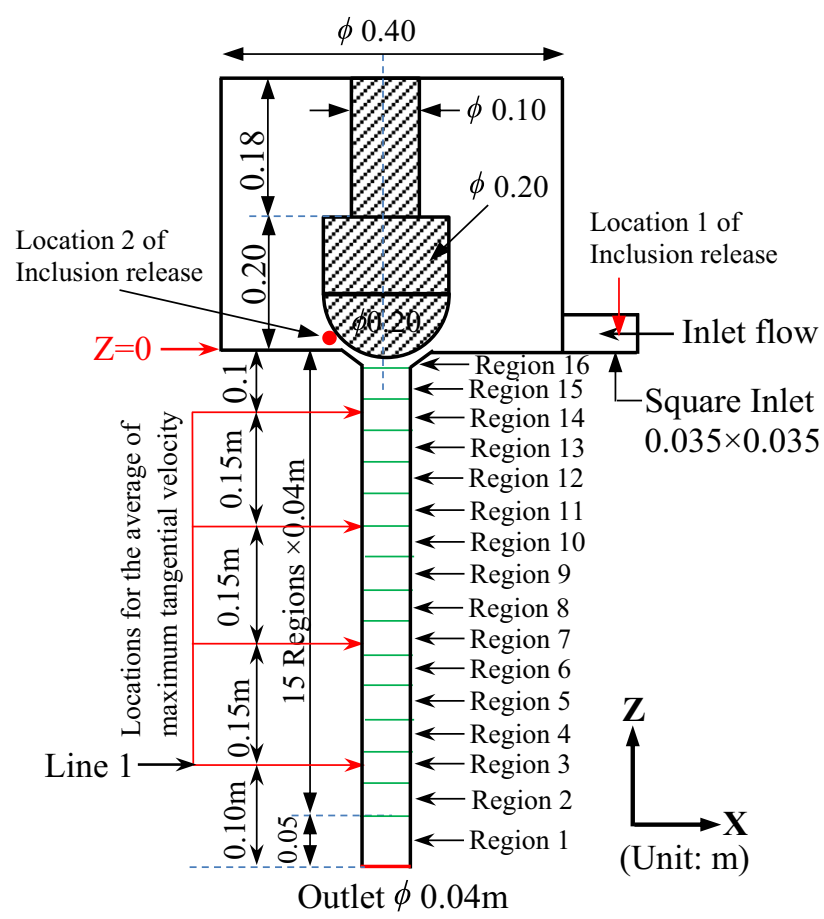

Fig. 1- Geometry of the new tundish design and the location of different SEN wall regions.

(4) A one-way coupling between steel and inclusions was used; i.e., the influence that inclusions have on the steel flow was not considered.

\section{B. Lagrangian Particle Tracking Model}

The locations of inclusions were obtained by solving the following equation:

$$
\boldsymbol{u}_{\mathrm{p}}=\frac{d \boldsymbol{x}_{\mathrm{p}}}{d t}
$$

where $\boldsymbol{x}_{\mathrm{p}}$ is the inclusion position and $\boldsymbol{u}_{\mathrm{p}}$ is the inclusion velocity. The inclusion velocity was obtained by solving the following momentum equation:

$$
\begin{aligned}
\frac{d \boldsymbol{u}_{\mathrm{p}}}{d t}= & \frac{\left(\boldsymbol{u}-\boldsymbol{u}_{\mathrm{p}}\right)}{\tau_{\mathrm{r}}}+\boldsymbol{g}\left(1-\frac{\rho_{\mathrm{f}}}{\rho_{\mathrm{p}}}\right)+\frac{1}{2} \frac{\rho_{\mathrm{f}}}{\rho_{\mathrm{p}}}\left(\boldsymbol{u}_{\mathrm{p}} \nabla \boldsymbol{u}-\frac{d \boldsymbol{u}_{\mathrm{p}}}{d t}\right) \\
& +\frac{\rho_{\mathrm{f}}}{\rho_{\mathrm{p}}} \boldsymbol{u}_{\mathrm{p}} \nabla \boldsymbol{u}+\frac{2 K v^{\frac{1}{2}} \rho_{\mathrm{f}} S_{i j}}{\rho_{\mathrm{p}} d_{\mathrm{p}}\left(S_{\mathrm{lk}} S_{\mathrm{kl}}\right)^{\frac{1}{4}}}\left(\boldsymbol{u}-\boldsymbol{u}_{\mathrm{p}}\right)
\end{aligned}
$$

where the first term on the right-hand side is the drag force per unit inclusion mass, the second term on the right-hand side is the force per unit inclusion mass due to gravity and buoyancy, the third term on the righthand side is the virtual mass force per unit inclusion mass, and the fourth term on the right-hand side is the pressure gradient force per unit inclusion mass. The fifth term on the right-hand side is the Saffman's lift force ${ }^{[48,49]}$ Furthermore, $\tau_{\mathrm{r}}$ is the particle relaxation 
time and $R e_{\mathrm{d}}$ is the relative Reynolds number. They are expressed by the following equations:

$$
\begin{gathered}
\tau_{\mathrm{r}}=\frac{\rho_{\mathrm{p}} d_{\mathrm{p}}^{2}}{18 \mu} \frac{24}{C_{\mathrm{D}} R e_{\mathrm{d}}} \\
R e_{\mathrm{d}}=\frac{\rho_{\mathrm{f}} d_{\mathrm{p}}\left|\boldsymbol{u}-\boldsymbol{u}_{\mathrm{p}}\right|}{\mu}
\end{gathered}
$$

where $\boldsymbol{u}$ is the continuous-phase velocity; $\mu$ is the molecular viscosity of the fluid; $v$ is the kinematic viscosity of the fluid; $d_{p}$ is the diameter of an inclusion; and $\rho_{\mathrm{f}}$ and $\rho_{\mathrm{p}}$ are the densities of the fluid and the inclusion, respectively. Furthermore, $S_{i j}$ and $S_{\mathrm{lk}}$ are the deformation tensor, and $K$ is a constant, which is equal to $2.59 .{ }^{[49]}$

For spherical particles, the drag coefficient, $C_{\mathrm{D}}$, from Morsi and Alexander ${ }^{[50]}$ was used.

$$
C_{\mathrm{D}}=\left\{\begin{array}{lc}
24.0 / R e_{\mathrm{d}} & R e_{\mathrm{d}}<0.1 \\
\frac{22.73}{R e_{\mathrm{d}}}+\frac{0.0903}{R e_{\mathrm{d}}^{2}}+3.69 & 0.1<R e_{\mathrm{d}} \leq 1.0 \\
\frac{29.1667}{R e_{\mathrm{d}}}-\frac{3.8889}{R e_{\mathrm{d}}^{2}}+1.222 & 1.0<R e_{\mathrm{d}} \leq 10 \\
\frac{46.5}{R e_{\mathrm{d}}}-\frac{116.67}{R e_{\mathrm{d}}^{2}}+0.6167 & 10<R e_{\mathrm{d}} \leq 100 \\
\frac{98.33}{R e_{\mathrm{d}}}-\frac{2778}{R e_{\mathrm{d}}^{2}}+0.3634 & 100<R e_{\mathrm{d}} \leq 1000 \\
\frac{148.62}{R e_{\mathrm{d}}}-\frac{47500}{R e_{\mathrm{d}}^{2}}+0.357 & 1000<R e_{\mathrm{d}} \leq 5000 \\
-\frac{490.546}{R e_{\mathrm{d}}}+\frac{578700}{R e_{\mathrm{d}}^{2}}+0.46 & 5000<R e_{\mathrm{d}} \leq 10000 \\
-\frac{1662.5}{R e_{\mathrm{d}}}+\frac{5416700}{R e_{\mathrm{d}}^{2}}+0.5191 & 10000<R e_{\mathrm{d}} \leq 50000
\end{array}\right.
$$

For nonspherical particles, the following relationships for the drag coefficient suggested by Haider and Levenspiel $^{[51]}$ were used:

$$
C_{\mathrm{D}}=\frac{24}{R e_{\mathrm{sph}}}\left(1+b_{1} R e_{\mathrm{sph}}^{b_{2}}\right)+\frac{b_{3} R e_{\mathrm{sph}}}{b_{4}+R e_{\mathrm{sph}}}
$$

where

$$
\begin{gathered}
b_{1}=\exp \left(2.3288-6.4581 \phi+2.4486 \phi^{2}\right) \\
b_{2}=0.0964+0.5565 \phi
\end{gathered}
$$

$b_{3}=\exp \left(4.905-13.8944 \phi+18.4222 \phi^{2}-10.2599 \phi^{3}\right)$

$b_{4}=\exp \left(1.4681+12.2584 \phi-20.7322 \phi^{2}+15.8855 \phi^{3}\right)$

The shape factor, $\phi$, is defined as follows:

$$
\phi=\frac{S_{\mathrm{sph}}}{S}
$$

where $S_{\mathrm{sph}}$ is the surface area of a sphere having the same volume as the particle and $S$ is the actual surface area of the particle. $\mathrm{Re}_{\mathrm{sph}}$ is the relative Reynolds number based on the diameter of a sphere having the same volume as the particle, $d_{\mathrm{sph}}$. This $d_{\mathrm{sph}}$ value was used to calculate the particle mass and drag force.

In a swirling flow, nonmetallic inclusions, which are lighter than molten steel, may move toward the swirling flow center, due to the centripetal effect. In an inertial frame of reference, e.g., the Cartesian coordinate system used in this model, the centrifugal force does not truly exist. Calculations can be performed by using Newton's laws of motion and by considering the real existing forces, e.g., the drag force, lift force, virtual mass force, gravity force, buoyancy force, and pressure gradient force. The centripetal effect for the separation of light inclusions should mainly come from the pressure gradient force, which has been included in the particle momentum equation shown in Eq. [2].

\section{Particle Stochastic Turbulence Model}

In order to simulate the effect of the turbulent fluctuations on the inclusion motion, a stochastic turbulent model can be used. This approach was based on the eddy lifetime, ${ }^{[52]}$ which spawned the eddy-interaction models in which the fluid velocities (eddies) are assumed to be stochastic quantities. These remain constant for the lifetime of the eddy or, if shorter, the transit time of the particle through the eddy. ${ }^{[53]}$ Therefore, the continuous-phase velocity can be expressed by using the following equation:

$$
\boldsymbol{u}=\overline{\boldsymbol{u}}+\boldsymbol{u}
$$

where $\overline{\boldsymbol{u}}$ and $\boldsymbol{u}$ are the continuous-phase averaged velocity and the fluctuating component, respectively. $\overline{\boldsymbol{u}}$ is obtained by solving the Eulerian equations for the continuous phase. Moreover, $\boldsymbol{u}$ is calculated by the following equation:

$\boldsymbol{u}=\zeta \sqrt{\overline{u_{i}^{\prime 2}}}$

where $\zeta$ is a zero mean with a unit variance and is a normally distributed random number. $\sqrt{\overline{u_{i}^{\prime 2}}}$ is the root-mean-square local fluctuation velocity in the $i$ direction, which directly can be solved by using the RSM. Therefore, anisotropic turbulent fluctuations were taken into account in this article.

\section{RESULTS}

\section{A. Inclusion Motion in the Tundish}

In order to know the inclusion motion in the upper part of the tundish, inclusions of different sizes and shapes were released from location 1 (shown in Figure 1) near the tundish inlet. Figure 2 shows the inclusion trajectories in the cylindrical tundish. Here, 


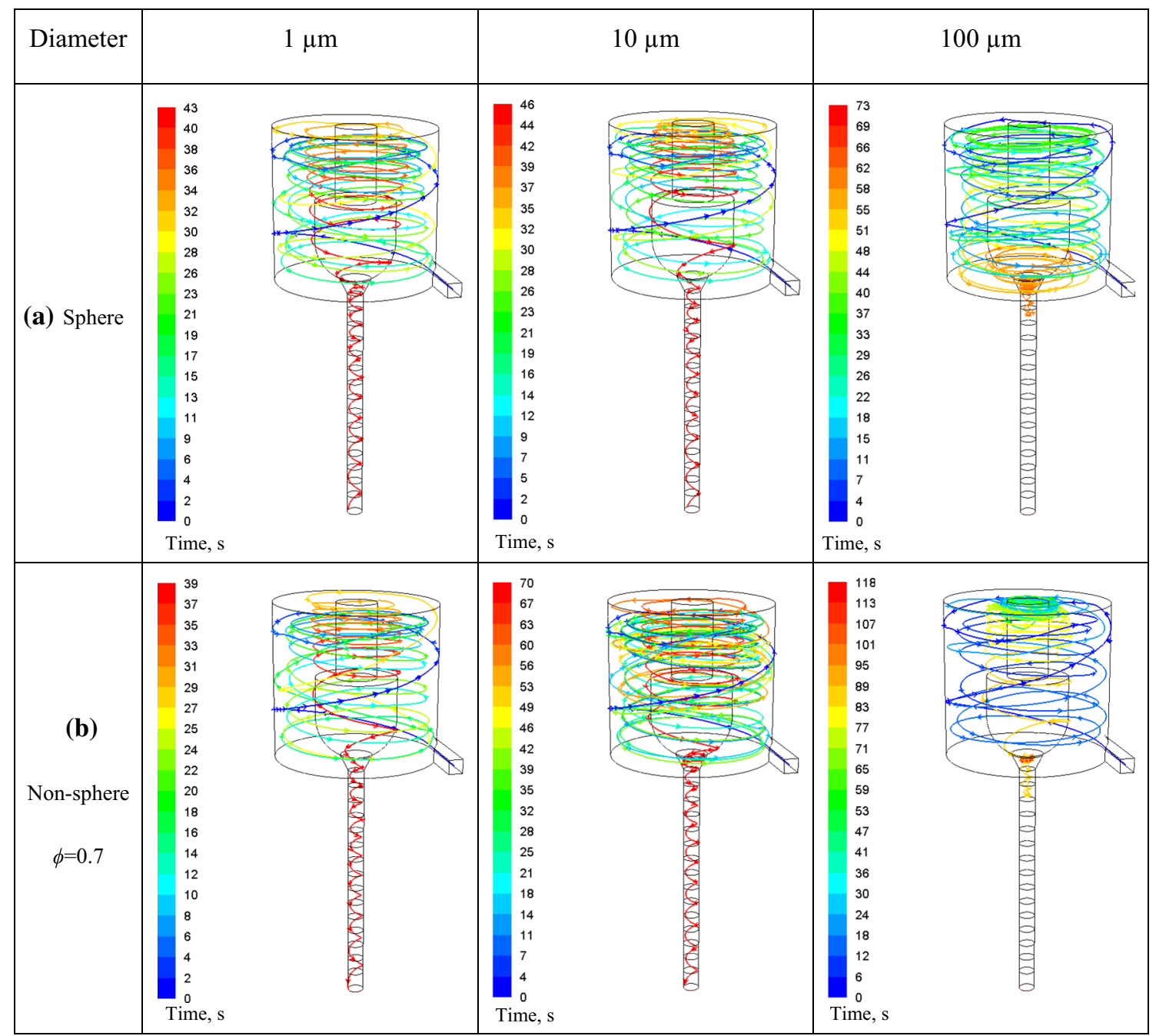

Fig. 2-Inclusion motions in the cylindrical tundish: (a) sphere inclusion and (b) nonsphere inclusion.

the stochastic turbulence model was not used to avoid the uncertainty induced by the turbulent fluctuations. Therefore, only the mean flow velocity was used when tracking the inclusion motion. This will give a general understanding of the motion behaviors of inclusions of different sizes and shapes in the tundish. It can be seen from Figure 2 that all the investigated inclusions, with the sizes of 1,10 , and $100 \mu \mathrm{m}$, are not able to stay at the top of the cylindrical tundish. This means that the buoyancy force was not high enough to keep these inclusions in the upper region. This is due to a large steel flow velocity at the top tundish region, with the value of around $0.7 \mathrm{~m} / \mathrm{s},{ }^{[42]}$ which also leads to a strong mixing. This strong rotational flow provides the required momentum for an intensive swirling flow later in the SEN. In addition, the residence time of inclusions in the cylindrical tundish increases with an increased inclusion size. This is because the buoyancy force always causes inclusions to float upward, where larger size inclusions obtain a larger buoyancy effect. This buoyancy reduces their velocity moving from the top of the tundish to the tundish bottom and, thus, increases their residence time. For inclusions with different shapes, a similar trajectory for $1-\mu \mathrm{m}$-size inclusions was observed, as shown in Figures 2(a) and (b). This means that the influence of the shape factor on their motion is small in the current investigation. However, for large inclusions, it was found that nonspherical inclusions have a longer residence time in the tundish compared to the spherical inclusions. In addition, $100-\mu \mathrm{m}$ inclusions of both spherical and nonspherical types were found to stay inside the SEN center after that they entered the SEN region. This is due to the centripetal separation effect, which causes inclusions to move toward the center, and due to the buoyancy effect, which makes them move upward.

In order to know the inclusion motion in the swirling flow SEN, glass-bubble particles were released at location 2 (shown in Figure 1) near the SEN inlet. These particles have a density smaller than the density of water, with a value in the range of around 700 to 1000 $\mathrm{kg} / \mathrm{m}^{3}$. Furthermore, the particle sizes are in the range of around 50 to $1000 \mu \mathrm{m}$.

Figure 3 shows the particle location in the SEN obtained from the water model experiments and from the simulation. It can be seen that the inclusion locations 


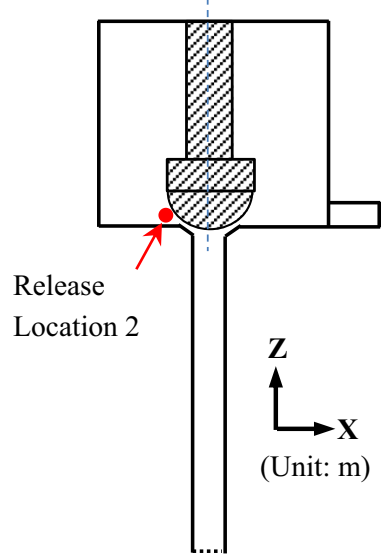

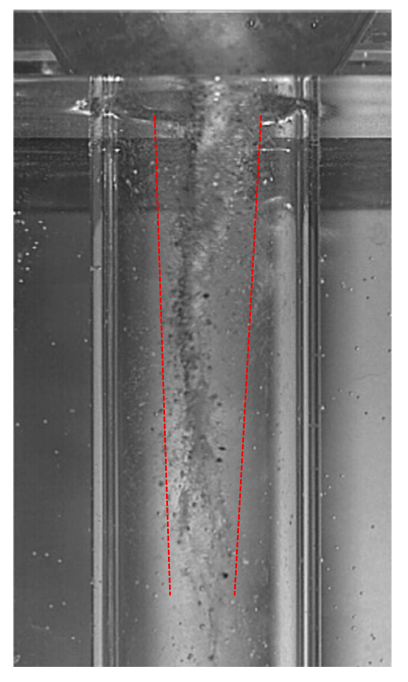

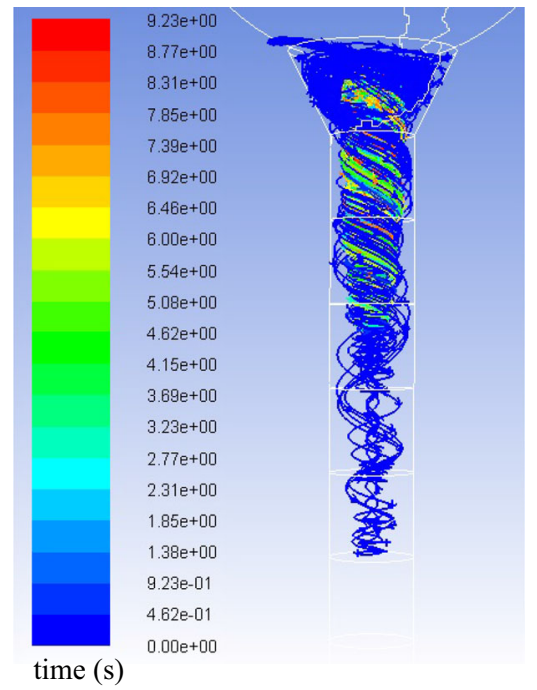

(b)

Fig. 3- (a) Particle location in the water model experiment and (b) trajectories of 100- $\mu$ m inclusion in the numerical simulation.

predicted by the numerical simulations are similar to the observations from the water model experiments. Specifically, Figure 3(a) shows that particles move toward the SEN center in the water flow. Thereafter, they stay in the center region of the SEN, where they rotate together with the swirling water flow. Figure 3(b) shows that $100-\mu \mathrm{m} \mathrm{Al}_{2} \mathrm{O}_{3}$ inclusions move toward the nozzle center and that they are located at the upper part of the SEN. This is due to the centripetal effect, the buoyancy effect, and the upward steel flow in the center of the swirling flow SEN, as shown in a previous study. ${ }^{[42]}$ In the simulations, $\mathrm{Al}_{2} \mathrm{O}_{3}$ inclusions have half the density of molten steel. However, in reality, it is difficult to find particles with a density that is just half of water's density. Normally, the density of particles used in water model experiments is close to but slightly smaller than the density of water, and it is in a range of values rather than having a certain value. Also, it is difficult to find particles with one particular size. They normally only can be found in a size range. In addition, it is difficult to observe very small particles, such as $100-\mu \mathrm{m}$ inclusions used in the simulations. According to the inclusion trajectory similarities between particles in water models and particles in simulations, the particle sizes in the water models and in the simulations should follow the relationship in Eq. [10] ${ }^{[54]}$ :

$$
\frac{r_{\mathrm{w}}}{r_{\mathrm{s}}}=\sqrt{\frac{\left(1-\frac{\rho_{\mathrm{p}}}{\rho_{\mathrm{l}}}\right)_{\mathrm{s}}}{\left(1-\frac{\rho_{\mathrm{p}}}{\rho_{\mathrm{l}}}\right)_{\mathrm{w}}}} \lambda^{-\frac{1}{4}}
$$

where $r_{\mathrm{w}}$ and $r_{\mathrm{s}}$ are the particle radius in the water model experiments and in the simulations, respectively. Furthermore, $\rho_{\mathrm{p}}$ and $\rho_{1}$ are the densities of particles and the liquid, respectively. The parameter $\lambda$ is the scale factor, which has a value of 1 in this article.

Table I shows the required sizes of different densities of glass-bubble particles used in water model experiments in order to simulate $100-\mu \mathrm{m} \mathrm{Al}_{2} \mathrm{O}_{3}$ inclusions,
Table I. Required Size of Different Particle Densities in Water Models to Simulate 100- $\mu \mathrm{m}$ Inclusions Present in Steel Flows

\begin{tabular}{lllll}
\hline Density $\left(\mathrm{kg} / \mathrm{m}^{3}\right)$ & 0.7 & 0.8 & 0.9 & 0.99 \\
Diameter $(\mu \mathrm{m})$ & 129 & 158 & 224 & 707 \\
\hline
\end{tabular}

which were tracked in the simulations in Figure 3(b). It can be seen that the required particle size in the water model to simulate $100-\mu \mathrm{m}$ inclusions in the steel flows is in the range of particle sizes (50 to $1000 \mu \mathrm{m}$ ) that were used in the current water model experiments. This means that the current water model can qualitatively illustrate the behavior of particles in the swirling flow and the results can be used to validate the numerical model predictions.

\section{B. Statistical Study on Inclusion Motion in the SEN}

In order to understand the inclusion behaviors in the swirling flow SEN, 1200 inclusions were released from location 2 (shown in Figure 1) to investigate their behaviors in the SEN. A doubling of the released inclusion number did not give an improved statistical result. Here, a particle was assumed to deposit on the wall once it touched the wall. The number of inclusions that deposited on the SEN wall is shown in Figure 4. It can be seen that the number of deposited inclusions of both spherical and nonspherical shapes shows initially a slight increase with an increased inclusion size. Thereafter, the results indicate a sharp decrease for the inclusion sizes ranging from 20 to $40 \mu \mathrm{m}$. For inclusions with sizes smaller than $20 \mu \mathrm{m}$, spherical inclusions have a bit larger deposited number compared to nonspherical inclusions. However, for large inclusions, a greater number of nonspherical inclusions were predicted to touch the wall, compared to the spherical inclusions. For example, the deposited number of $40-\mu \mathrm{m}$ 
nonspherical inclusions was found to be 27 pct higher than that of spherical inclusions.

Figure 5 shows the number of inclusions that deposited on the SEN wall in different regions. The locations of the different regions are shown in Figure 1. It can be seen that the numbers of different size inclusions, which are smaller than $20 \mu \mathrm{m}$, that deposited on the SEN wall show a similar distribution trend along the different SEN regions. In addition, for small size inclusions, the inclusion shape seems to have almost no, or only a slight, influence on their deposition behavior. In region 16, the largest number of deposited inclusions was found among all the regions. This region is located at the SEN inlet, which is closest to the inclusion release location. When inclusions move downward with the steel flow from region 16, the number of deposited inclusions shows a slight decrease. This may be due to the fact that the number concentration of inclusions close to the wall in the steel flow decreased, since inclusions may have deposited on the wall in the upper flow regions of the SEN. For large inclusions, e.g., $40-\mu \mathrm{m}$ inclusions, both spherical and nonspherical inclusions show a large difference with respect to the deposited number distribution along different SEN regions, compared to the small inclusions. From region 10 to region 15, a much smaller number of large inclusions were predicted to touch the wall. More

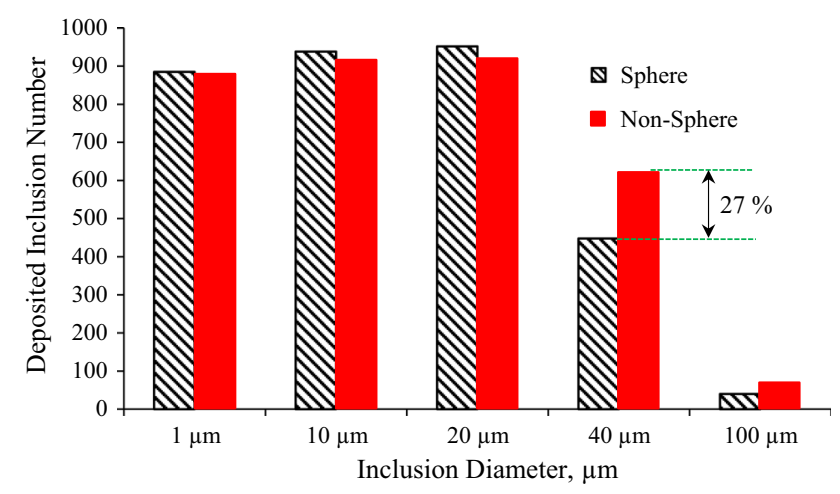

Fig. 4 -Deposited number of different sizes and shapes of inclusions. specifically, approximately one fifth of the number of deposited small size inclusions deposited on the wall. However, in the regions close to the SEN outlet, the number of large size inclusions that deposited on the SEN wall increased to a similar level as that of small size inclusions. Furthermore, a 40 pct larger number of $40-\mu \mathrm{m}$ nonspherical inclusions were found to touch the wall compared to spherical inclusions. However, for $100-\mu \mathrm{m}$ inclusions, both the spherical and nonspherical inclusions were found not to touch the SEN wall, except in region 16. This is due to the centripetal effect, which can be seen from the inclusion trajectories in Figure 3(b).

In order to understand why large amounts of inclusion are deposited in region 16, the steel flow in this SEN region is plotted in Figure 6. Figure 6(a) shows the steel flow paths from four points. The locations of these points are shown in Figure 6(b). The steel flow has two velocity components, as shown in Figure 6(a). One velocity component is directed toward the SEN center (this is the common situation in a conventional tundish), and another velocity component is directed in the tangential direction due to the rotational steel flow in the tundish. Due to the tangential flow component, the steel flow has difficulty reaching the center of the SEN. Instead, it tends to flow toward the SEN wall. After it gets close to the wall, its flow direction changes, due to the curved SEN wall, to form a swirl flow. In addition, steel flow paths from different points are different. This illustrates that a nonuniform SEN inlet flow exists. This can be seen clearly from Figures 6(c) through (f), where the tangential velocities of the steel flow in different cross sections of the SEN in region 16 are plotted. The steel flow field is not uniform and the maximum velocity is larger than $5 \mathrm{~m} / \mathrm{s}$. A swirling flow is developing in this region and it is uneven and chaotic. As the steel flows downward in the SEN, the maximum steel flow velocity decreases and the velocity distribution in the cross section tends to become a developed flow. This means that the swirling flow is under development in region 16 (shown in Figure 1).

Figure 7 shows the steel flow properties in the middle $X Z$ plane of the SEN. It can be seen that a recirculating

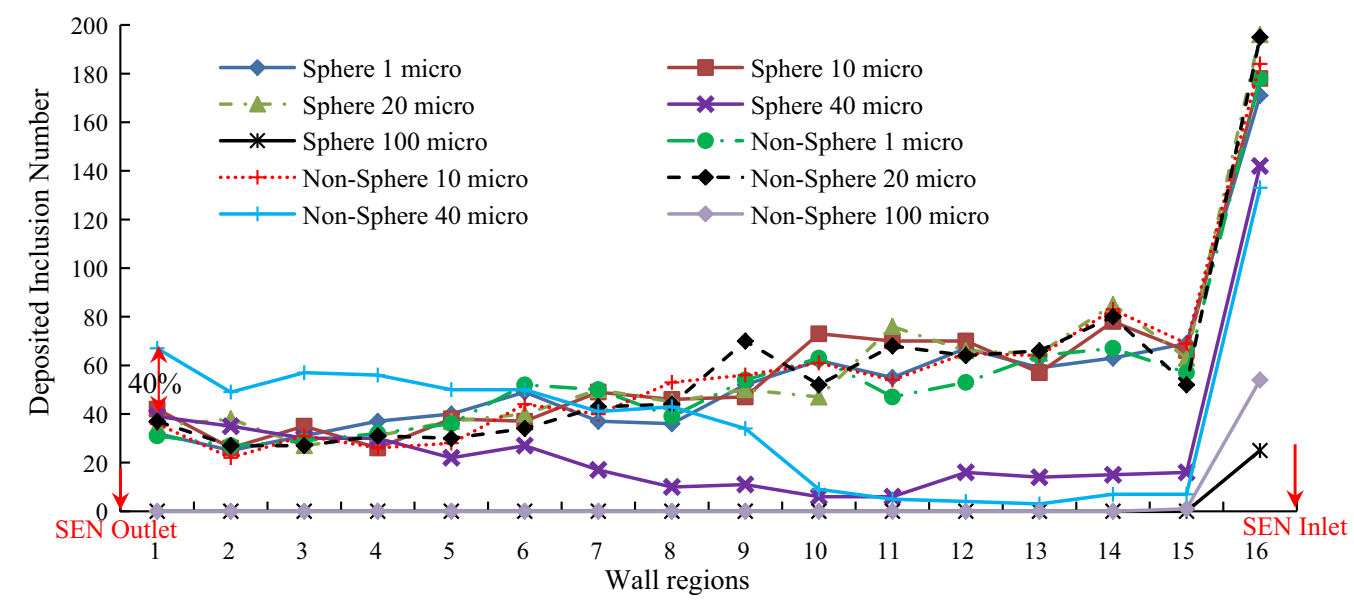

Fig. 5-Number of inclusions deposited on the SEN wall at different regions (the regions are shown in Fig. 1). 


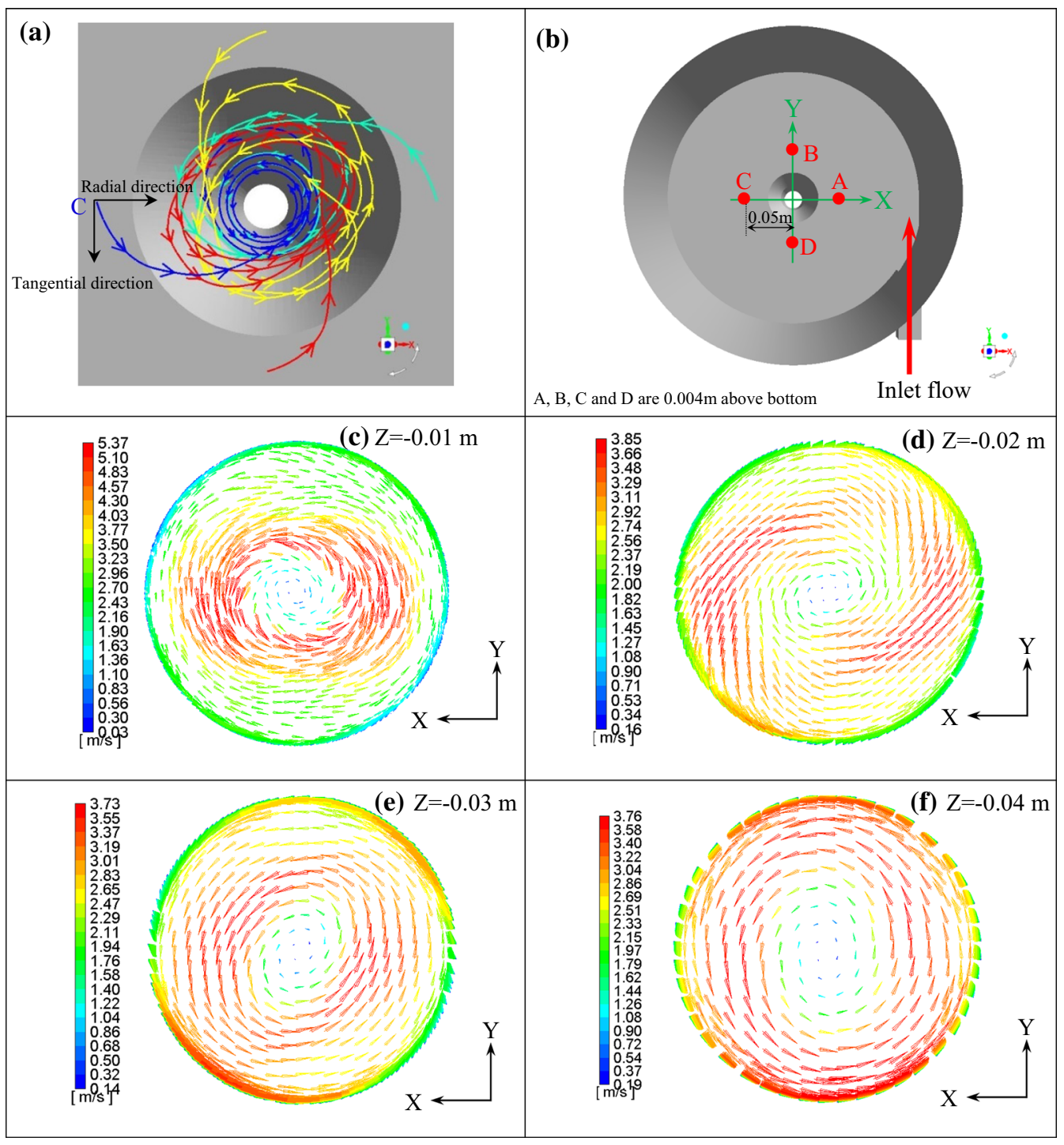

Fig. 6 - Steel flow at the SEN inlet region: $(a)$ flow streamlines, $(b)$ locations of the streamlines, $(c)$ tangential velocity at the cross section $Z=$ $-0.01 \mathrm{~m},(d)$ tangential velocity at the cross section $Z=-0.02 \mathrm{~m},(e)$ tangential velocity at the cross section $Z=-0.03 \mathrm{~m}$, and $(f)$ tangential velocity at the cross section $Z=-0.04 \mathrm{~m}$.

flow exists in the SEN inlet region. The formation of the recirculating flow is partly due to the flow separation, which takes place when the steel enters the SEN. The recirculating flow due to flow separation can also be found commonly in some other flows, e.g., the flow along a curved wall or jet flows. ${ }^{[55]}$ In addition, in a swirling flow, the steel flow also has a tangential velocity, as shown in Figure 6(a). After the steel moves into the SEN, its tangential momentum will direct the steel flowing toward the SEN wall. Then, the flow direction will change due to the curved SEN wall to form a swirl flow. This will also create a high-pressure region near the wall, as shown in Figure 7(b). Therefore, both the flow separation and the rotational flow momentum affect the flow direction to form the recirculating flow, as shown in Figure 7(a). In addition, Figure 7(c) shows that the steel flow has a high turbulent kinetic energy in region 16 . This increases the probability of inclusions, which are a bit far away from the turbulent boundary, to obtain energy from their interaction with turbulence eddies and to move toward the near-wall boundary. As the inclusions reach the turbulent boundary layer, their transport toward the wall will be influenced by the "turbophoresis effect." $[16,17,56]$

From Figures 6 and 7, it can be concluded that the high inclusion deposition in region 16 is due to the steel flow characteristics, e.g., a recirculating and chaotic flow. These factors provide inclusions with a greater chance of depositing in this region. Figure 8 shows the inclusion trajectories in the SEN. Ten spherical inclusions with the diameter of $10 \mu \mathrm{m}$ were released from four points that are shown in Figure 7(b). It can be seen that inclusions have different paths compared to the steel flow path in Figure 6(a). This is due to the turbulent fluctuations in the fluid. After inclusions are transported into the SEN, some inclusions move upward toward the SEN inlet and they deposit there. This can be observed from Figures 8(a), (b), and (d). 


\begin{tabular}{|c|c|c|}
\hline (a) Velocity Vector, $\mathrm{m} / \mathrm{s}$ & (b) Static Pressure, $\mathrm{Pa}$ & (c) Turbulence Kinetic Energy, $\mathrm{m}^{2} / \mathrm{s}^{2}$ \\
\hline 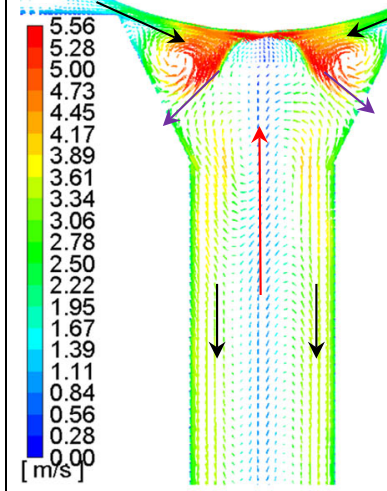 & 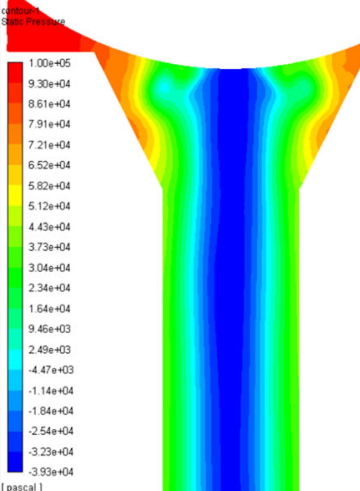 & $\begin{array}{l}0.15 \\
0.14 \\
0.14 \\
0.13 \\
0.12 \\
0.11 \\
0.11 \\
0.10 \\
0.09 \\
0.08 \\
0.08 \\
0.07 \\
0.06 \\
0.05 \\
0.05 \\
0.04 \\
0.03 \\
0.02 \\
0.02 \\
0.01 \\
0.902\end{array}$ \\
\hline
\end{tabular}

Fig. 7-Steel flow properties at the $X Z$ middle plane of the SEN: $(a)$ velocity vector, $(b)$ static pressure, and (c) turbulent kinetic energy.

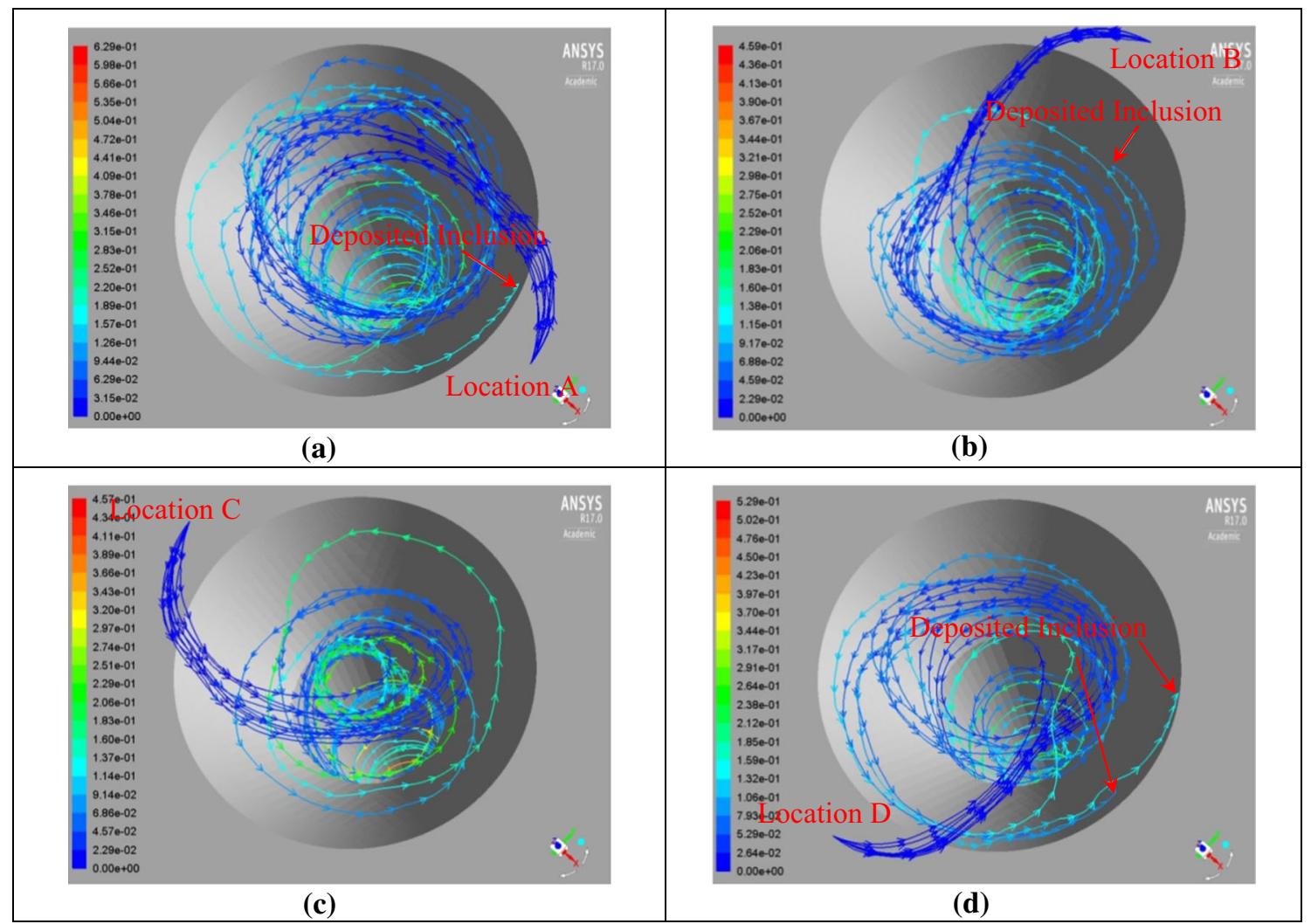

Fig. 8-Trajectories of inclusions released from different locations: (a) inclusions released from location A, $(b)$ inclusions released from location $\mathrm{B},(c)$ inclusions released from location $\mathrm{C}$, and $(d)$ inclusions released from location $\mathrm{D}$.

This is due to the recirculating flow, as shown in Figure 7(a).

\section{DISCUSSION}

Behaviors of different sizes and shapes of $\mathrm{Al}_{2} \mathrm{O}_{3}$ inclusions in the swirling steel flow of the new cylindrical tundish design were investigated. This was done based on the assumption that interactions among inclusions are ignored. The reason for this assumption is that the volume fraction of inclusions in steel flows is very small. In the new tundish design, it was found to be difficult for the inclusions to stay at the top tundish region due to the high rotational velocity in the tundish. Therefore, the removal of inclusions in the current design is hard to accomplish. Thus, a method, such as argon gas protection, instead of top slag should be used to avoid the 


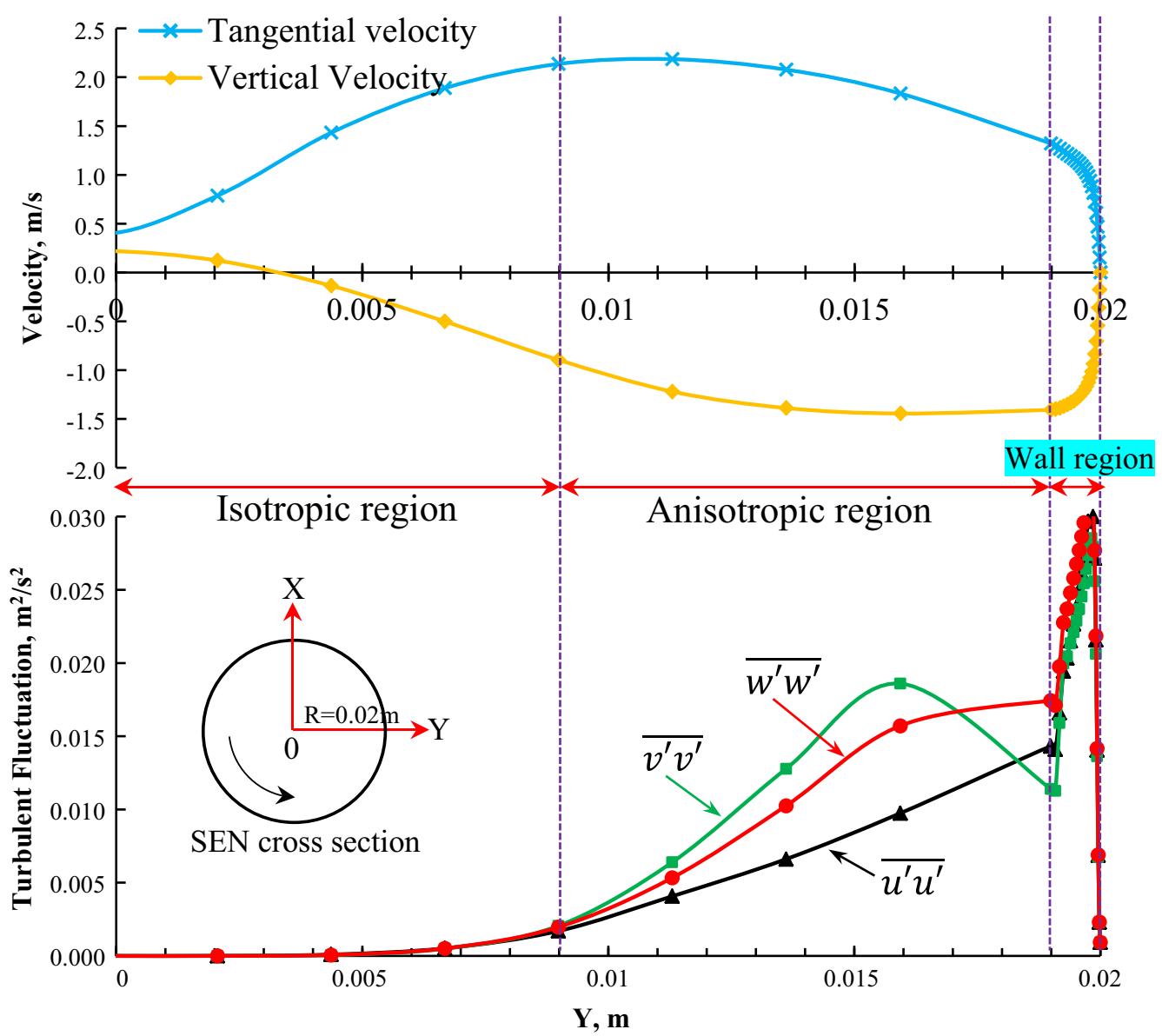

Fig. 9-Steel flow velocity and Reynolds stresses in different directions along line 1 in the SEN $\left(\overline{u^{\prime} u^{\prime}}\right.$ fluctuation is in rotational direction, $\overline{v^{\prime} v^{\prime}}$ fluctuation is in radial direction, and $\overline{w^{\prime} w^{\prime}}$ fluctuation is in downward direction).

Table II. Stokes Number of Different Sized Spherical Inclusions in the Swirling Flow SEN

\begin{tabular}{lccr}
\hline & \multicolumn{3}{c}{ Stokes Number } \\
\cline { 2 - 4 } Diameter $(\mu \mathrm{m})$ & Shear Stress, 150 Pa & Shear Stress, 200 Pa & Shear Stress, 250 Pa \\
\hline 1 & $7.12 \times 10^{-4}$ & $9.49 \times 10^{-4}$ & $1.19 \times 10^{-3}$ \\
10 & $7.12 \times 10^{-2}$ & $9.49 \times 10^{-2}$ & $1.19 \times 10^{-1}$ \\
20 & $2.85 \times 10^{-1}$ & $3.80 \times 10^{-1}$ & $4.75 \times 10^{-1}$ \\
40 & 1.14 & 1.52 & 1.90 \\
100 & 7.12 & 9.49 & 11.87 \\
\hline
\end{tabular}

reoxidation of steel by air. In the SEN inlet region, many inclusions were predicted to deposit on the wall. This may be due to the complex steel flow, where both a recirculating flow and an intensive turbulent flow existed. In addition, the steel flow path in Figure 6(a) and the inclusion trajectories in Figure 8 in the SEN inlet region show that the inlet flow is not uniform. Therefore, an improved design is required in the future, which aims not to influence the swirling flow intensity. However, it should reduce the inclusion deposition as well as the possibility for clogging. For example, a smooth transition with a curved inner wall surface at the connection region between the SEN and the tundish bottom may be a helpful way to obtain a stable steel flow, and to reduce the inclusion deposition there. For different shapes of inclusions, it was found that the influence of the shape factor of inclusions is more important for large size inclusions compared to small size inclusions. This can be easily seen from the results in Figure 4, where the deposited number of nonspherical inclusions is around 27 pet higher compared to that of spherical inclusions. In addition, the interaction between nonspherical inclusions, such as the faceted inclusions, and the refractory wall seems like a plane-plane type interaction. According to the research by Zheng et al., ${ }^{[57]}$ this kind of interaction is stronger compared to a sphere-plane type interaction, namely, the interaction between a spherical inclusion and a refractory wall. This 
means that nonspherical inclusions may easily stick to the wall once they move close to the wall compared to spherical inclusions. Therefore, nonspherical inclusions may lead to more serious clogging problems compared to spherical inclusions. The current investigation about the influence of inclusion shape is simple and is based on a shape factor that is determined by a corrected drag coefficient. In steel flows, a large number of inclusions are clusters with an irregular shape. Therefore, efforts are still required to make the inclusion tracking more realistic.

Simulations of the steel flow in the new tundish have been carried out by using the RSM combined with the Stress-Omega submodel. ${ }^{[42]}$ The fluid flow and the anisotropy of the turbulent fluctuations in the near-wall boundary layer have been solved, since they have been found to be important for the predictions of particle depositions in turbulent flows. ${ }^{[40]}$ Figure 9 shows the predicted Reynolds stresses in three directions along line 1 in the swirling flow SEN. Line 1 presents data from the SEN center to the wall in the $Y$-axis in the SEN cross section of $0.55 \mathrm{~m}$ below the tundish bottom, as shown in Figure 1. It can be seen that there are three regions in the swirling flow with different turbulent fluctuation behaviors. In the SEN core region, the turbulent fluctuations are similar in the different directions, with values of the Reynolds stresses approaching zero at the SEN center. This means that isotropic turbulent fluctuations exist here and that the steel flow is stable with weak turbulence fluctuations. Outside the isotropic fluctuation region, there is an anisotropic turbulent fluctuation region. Here, the tangential steel flow velocity gradually decreases toward the SEN wall. However, the vertical velocity first increases to its maximum value at the location near the turbulent boundary layer. Then, it decreases to zero at the wall due to a nonslip boundary condition. This is due to the centrifugal effect. The rotational steel flow tends to move to the SEN wall due to its inertia. This creates a high pressure at the near-wall region and a very small pressure at the SEN center region. ${ }^{[42]}$ The high pressure at the near-wall region combined with the downward gravity leads to a high downward steel flow velocity. However, the momentum of the inertial tangential steel flow will decrease after steel reaches close to the wall. This is due to the high flow shear resulting from the flow direction change because of the curved wall. This can be seen clearly from the high wall shear stress in a previous study, with the values in the range of around 100 to 300 $\mathrm{Pa}$ on the SEN wall. ${ }^{[42]}$ Therefore, the steel flow in this region has a high velocity, a high flow shear, and high anisotropic turbulent fluctuations. These kinds of flow characteristics are difficult to accurately resolve by using a $k-\varepsilon$ type turbulent model, which is especially true when the swirling flow intensity is very high. Thus, the inclusion tracking ${ }^{[32-34]}$ based on a $k-\varepsilon$ type model solution faces some challenges to obtain a good description of inclusion motion. In the near-wall region, a high gradient of turbulent fluctuation exists, which leads to a strong turbophoresis effect. ${ }^{[16,17,56]}$ This has been considered in the current study with the RSM to resolve the turbulent boundary layer, while it was ignored in previous studies. ${ }^{[32-34]}$

The effect of a swirl flow on the inclusion separation is an important concern for a swirling flow SEN. This is due to the fact that light inclusions might be separated by the swirling flow due to their lower density than steel. The interaction between a particle and a fluid can generally be evaluated by the Stokes number, which can be expressed as follows:

$$
\begin{array}{r}
\mathrm{St}_{\mathrm{V}}=\tau_{\mathrm{p}} / \tau_{\mathrm{f}} \\
\tau_{\mathrm{p}}=\frac{\rho_{\mathrm{p}} d_{\mathrm{p}}^{2}}{18 \mu}
\end{array}
$$

where $\tau_{\mathrm{p}}$ is the particle momentum (velocity) response time and $\tau_{\mathrm{f}}$ is the characteristic time of the flow field $\tau_{\mathrm{f}}=\frac{v}{u_{\tau}^{2}}{ }^{[58,59]}$ The parameter $u_{\tau}$ is the friction velocity, which can be evaluated by using the following expression: $u_{\tau}=\sqrt{\tau_{\mathrm{s}} / \rho_{\mathrm{f}}}$, where $\tau_{\mathrm{s}}$ is the wall shear stress. The Stokes number is a ratio of the response time of the particles to the characteristic time associated with the flow field.

Table II shows the values of the Stokes number of spherical inclusions of different sizes in the swirling flow SEN. The values of the wall shear stress needed in the calculations are taken from a previous study, ${ }^{[42]}$ where the flow field for the same setup as the current study was calculated and is, therefore, not repeated in the current study. The values of 150,200 , and $250 \mathrm{~Pa}$ were used to calculate the Stokes number of different size inclusions, since the values of the shear stresses on the SEN wall are mostly in this range ${ }^{[42]}$ It can be seen that the Stokes number of small size inclusions, e.g., $1 \mu \mathrm{m}$, is very small. This illustrates that small size inclusions can firmly follow the steel flow and that they are difficult to separate in the current swirling flow SEN. Inclusions with a diameter of $40 \mu \mathrm{m}$ have a Stokes number larger than 1. This illustrates that their response time is larger than their flow characteristic time. Therefore, these inclusions will not firmly follow the steel flow path. This gives light inclusions the chance or time to respond to other forces, e.g., to be separated in a swirling flow due to the centripetal effect. As shown in Figure 7(b), a large pressure gradient exists from the SEN wall to the SEN center. This may cause a separation of light nonmetallic inclusions toward the swirling flow center.

The Stokes number only gives the particle response ability to the flow change. However, it cannot describe the separation ability of light inclusions in a swirling steel flow. The separation of light inclusions in a swirling fluid flow, which results from a centripetal force in the radial direction of the cylindrical coordinates or a pressure gradient force in an inertial frame of reference, depends on the relationship between the scale of the particle residence time and the scale of the centripetal separation time. Therefore, a dimensionless number was defined in this article to describe the separation ability of light inclusions. This is the Separation number, which 
may be expressed as $S=\tau_{\text {res }} / \tau_{\mathrm{c}}$ and which represents the ratio of the above two timescales. Here, $\tau_{\text {res }}$ represents the existing time of a particle in a swirling flow and $\tau_{\mathrm{c}}$ represents the time required for the particle to move a distance equal to the pipe radius in the radial direction of a swirling flow. If $\tau_{\text {res }} \gg \tau_{\mathrm{c}}$, it means that the particle has enough existing time in the swirling flow and may be separated by the centripetal force. However, if $\tau_{\text {res }} \ll \tau_{\text {c }}$, it means that the particle passes the swirling flow so quickly that it has no time to respond to the centripetal force. Therefore, the Separation number represents the ability of a particle to be separated to move toward the swirling flow center or outside when it is present in a swirling flow. In a cylindrical coordinate system, the centripetal separation time scale, $\tau_{\mathrm{c}}$, can be calculated by using the following equations by considering the drag force and the centripetal force in the radial direction: ${ }^{[34]}$

$$
\begin{gathered}
\tau_{\mathrm{c}}=R / v_{\mathrm{p}, \mathrm{r}} \\
\frac{\left(u_{\mathrm{f}, \mathrm{r}}-v_{\mathrm{p}, \mathrm{r}}\right)}{\tau_{\mathrm{p}}}+\frac{1}{r}\left(\frac{\rho_{\mathrm{f}}}{\rho_{\mathrm{p}}} u_{\mathrm{f}, \theta}^{2}-v_{\mathrm{p}, \theta}^{2}\right)=0 \\
\tau_{\mathrm{p}}=\frac{\rho_{\mathrm{p}} d_{\mathrm{p}}^{2}}{18 \mu}
\end{gathered}
$$

where $R$ is the radius of the SEN and $u_{\mathrm{f}, \theta}$ and $v_{\mathrm{p}, \theta}$ are the tangential velocity of the fluid and particle, respectively. Furthermore, $v_{\mathrm{p}, \mathrm{r}}$ is the particle centripetal velocity. It can be obtained with the assumption that the radial fluid velocity, $u_{\mathrm{f}, \mathrm{r}}$, and the tangential particle velocity, $v_{\mathrm{p}, \theta}$, are equal to $0 \mathrm{~m} / \mathrm{s}$, respectively. The particle residence time in the swirling flow can either be obtained by tracking a particle using a Lagrangian tracking scheme by using commercial software or be evaluated by using Eq. [17] to consider the force balance, including the drag, gravity, and buoyancy forces:

$$
\begin{gathered}
\tau_{\text {res }}=L / v_{\mathrm{p}, \mathrm{a}} \\
\frac{\left(u_{\mathrm{f}, \mathrm{a}}-v_{\mathrm{p}, \mathrm{a}}\right)}{\tau_{\mathrm{p}}}+g\left(1-\frac{\rho_{\mathrm{f}}}{\rho_{\mathrm{p}}}\right)=0
\end{gathered}
$$

where $L$ is the length of the swirling flow in the axial direction with a value of $0.65 \mathrm{~m}$ in the current study. The parameters $u_{\mathrm{f}, \mathrm{a}}$ and $v_{\mathrm{p}, \mathrm{a}}$ are the fluid and particle velocity in the axial direction of cylindrical coordinates, respectively. The parameter $u_{\mathrm{f}, \mathrm{a}}$ can simply be represented by using the average velocity in the axial direction. It is assumed to have a value of $1.1 \mathrm{~m} / \mathrm{s}$ in the current study.

The Separation number for different sizes of spherical $\mathrm{Al}_{2} \mathrm{O}_{3}$ inclusions in the swirling flow $\mathrm{SEN}$ is shown in Figure 10. The average maximum tangential velocity, $u_{\mathrm{f}, \theta}=2.625 \mathrm{~m} / \mathrm{s}$, on four cross sections (shown in

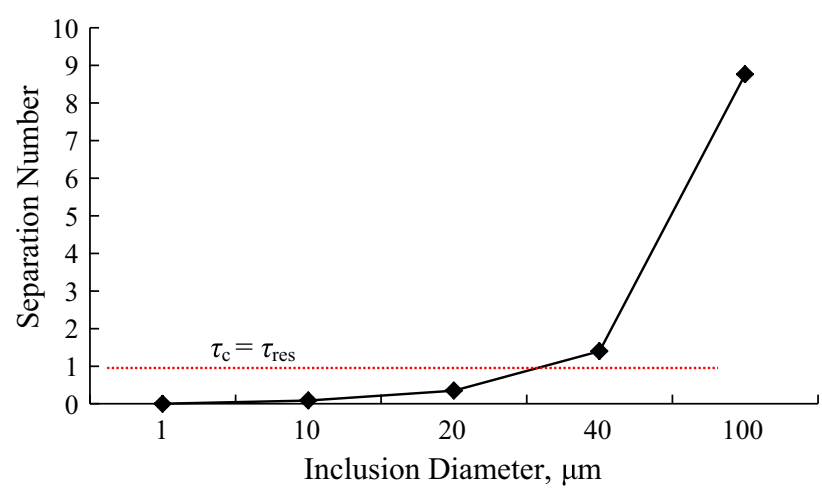

Fig. 10-Separation number of different inclusion sizes in the current study.

Figure 1) of the SEN and its distance to the SEN center, $r=0.014 \mathrm{~m}$, were used in the calculation. It can be seen that small inclusions have a very small separation number, such as a value of $8.7 \times 10^{-4}$ for a $1-\mu \mathrm{m}$ inclusion. This illustrates that they cannot be separated in the current swirling flow. At a point when the inclusion size is in the range of 20 to $40 \mu \mathrm{m}$, the particle residence time is equal to the centripetal time. For $40-\mu \mathrm{m}$ inclusions, the separation number is 1.4 , which illustrates that inclusions of this size have the possibility to be separated in the current swirling flow. This also explains the large performance difference for the different sizes of $\mathrm{Al}_{2} \mathrm{O}_{3}$ inclusions, as shown in Figure 4. More specifically, the deposited number of $40-\mu \mathrm{m}$ inclusions is much smaller than that of $20-\mu \mathrm{m}$ inclusions, due to their movement toward the SEN center because of the centripetal effect. Therefore, the defined Separation number is a useful dimensionless number to describe the particle separation ability in a swirling flow.

The calculated swirl number in the swirling flow SEN was in the range of around 1.08 to 1.6, which indicates a strong swirling flow. ${ }^{[42]}$ It was found effective in reducing the deposition of large size inclusions. In the current swirling flow, a high wall shear stress exists. This may be beneficial to prevent the attachment of inclusions on the SEN wall. At the same time, a high shear stress may also produce new inclusions due to the erosion of the refractory. This issue should be experimentally verified in the future. In addition, inclusions were assumed to deposit on the SEN wall once they touch the wall. This is due to the fact that the particle-wall interaction is a complex phenomenon. Thus, a "stick" wall boundary condition is commonly used. In reality, some inclusions may move back to the steel flow rather than stick on the SEN wall after they touch the wall. Therefore, it is necessary to develop a new model to describe the particle behavior on the liquid-wall interface.

\section{CONCLUSIONS}

The behaviors of different sizes and shapes of inclusions in a newly designed tundish were investigated by using a Lagrangian particle tracking method. The main conclusions for this study are as follows. 
1. Inclusions in the cylindrical tundish are difficult to remove, since a strong rotational flow exists at the region near the top surface of the tundish. This high rotational flow provides the required momentum for a strong swirling flow later inside the SEN.

2. The inclusion deposition in the swirling flow SEN was studied. It was found that large size inclusions have a smaller number of deposited inclusions, compared to small size inclusions. This means that the swirling flow is effective in separating large size inclusions, e.g., 40 and $100 \mu \mathrm{m}$. These large inclusions have a Separation number larger than 1. For nonspherical inclusions, large size inclusions have around 27 pct higher number of deposited inclusions compared to spherical inclusions.

3. The swirling steel flow shows three regions, namely, the center isotropic turbulent region, the anisotropic turbulent region, and the near-wall region. In order to have a good description of the inclusion motion in this complex flow, the anisotropic turbulent fluctuations should be taken into account.

4. In the SEN inlet region, some inclusions deposited on the wall. The plotted velocity distribution shows that the SEN inlet flow is not uniform and that the flow is very chaotic. It has a high turbulent kinetic energy in this region, and a recirculating flow exists there. These flow phenomena promote the inclusion deposition in this region. Therefore, a further improved design of the SEN inlet region should be developed in the future to reduce the probability of an inclusion deposition.

\section{ACKNOWLEDGMENTS}

One of the authors (PN) thanks the National Natural Science Foundation of China (Grant No. 51704062) for the support on this work.

\section{OPEN ACCESS}

This article is distributed under the terms of the Creative Commons Attribution 4.0 International License (http://creativecommons.org/licenses/by/4.0/), which permits unrestricted use, distribution, and reproduction in any medium, provided you give appropriate credit to the original author(s) and the source, provide a link to the Creative Commons license, and indicate if changes were made.

\section{REFERENCES}

1. K. Chattopadhyay, M. Isac, and R.I.L. Guthrie: ISIJ Int., 2010, vol. 50 , pp. $331-48$.

2. Y. Sahai: Metall. Mater. Trans. B, 2016, vol. 47B, pp. 2095-2106.

3. Y. Miki and B.G. Thomas: Metall. Mater. Trans. B, 1999, vol. 30B, pp. 639-54.

4. H. Ling and L. Zhang: JOM, 2013, vol. 65, pp. 1155-63.

5. L. Zhang: Steel Res. Int., 2005, vol. 76, pp. 784-96.
6. C. Chen, P. Ni, L.T.I. Jonsson, A. Tilliander, G. Cheng, and P.G. Jönsson: Metall. Mater. Trans. B, 2016, vol. 47B, pp. 1916-32.

7. L. Zhang, S. Taniguchi, and K. Cai: Metall. Mater. Trans. B, 2000, vol. 31B, pp. 253-66

8. R. Schwarze, F. Obermeier, J. Hantusch, A. Franke, and D. Janke: Steel Res. Int., 2001, vol. 72, pp. 215-20.

9. Q. Yuan, B.G. Thomas, and S.P. Vanka: Metall. Mater. Trans. B, 2004, vol. 35B, pp. 703-14

10. L. Zhang, Y. Wang, and X. Zuo: Metall. Mater. Trans. B, 2008, vol. 39B, pp. 534-50.

11. M. Mohammadi-Ghaleni, M.A. Zaeem, J.D. Smith, and R. O'Malley: Metall. Mater. Trans. B, 2016, vol. 47B, pp. 3056-65.

12. E. Gutiérrez, S. Garcia-Hernandez, and J.J. Barreto: ISIJ Int., 2016, vol. 56, pp. 1394-1403.

13. E. Gutiérrez, S. Garcia-Hernandez, and J.J. Barreto: Steel Res. Int., 2016, vol. 87, pp. 1406-16.

14. M. Long, X. Zuo, L. Zhang, and D. Chen: ISIJ Int., 2010, vol. 50, pp. $712-20$.

15. P. Ni, L.T.I. Jonsson, M. Ersson, and P.G. Jönsson: Steel Res. Int., 2017, vol. 88, Article No. 1600155.

16. P. Ni, L.T.I. Jonsson, M. Ersson, and P.G. Jönsson: Int. J. Multiphase Flow, 2014, vol. 62, pp. 152-60.

17. P. Ni, L.T.I. Jonsson, M. Ersson, and P.G. Jönsson: Metall. Mater. Trans. B, 2014, vol. 45B, pp. 2414-24.

18. Z. Liu and B. Li: Powder Technol., 2016, vol. 287, pp. 315-29.

19. B. Li and F. Tsukihashi: ISIJ Int., 2003, vol. 43, pp. 923-31.

20. Y. Ho and W. Hwang: ISIJ Int., 2003, vol. 43, pp. 1715-23.

21. H. Yu and M. Zhu: ISIJ Int., 2008, vol. 48, pp. 584-91.

22. S. Lei, J. Zhang, X. Zhao, and K. He: ISIJ Int., 2014, vol. 54, pp. 94-102.

23. Y. Wang, A. Dong, and L. Zhang: Steel Res. Int., 2011, vol. 82, pp. $428-39$.

24. L. Zhang, J. Aoki, and B.G. Thomas: Metall. Mater. Trans. B, 2006, vol. 37B, pp. 361-79.

25. B.G. Thomas, Q. Yuan, S. Mahmood, R. Liu, and R. Chaudhary: Metall. Mater. Trans. B, 2014, vol. 45B, pp. 22-35.

26. S. Yokoya, Y. Asako, S. Hara, and J. Szekely: ISIJ Int., 1994, vol. 34 , pp. $883-88$.

27. S. Yokoya, R. Westoff, Y. Asako, S. Hara, and J. Szekely: ISIJ Int., 1994, vol. 34, pp. 889-95.

28. S. Yokoya, S. Takagi, M. Iguchi, Y. Asako, R. Westoff, and S. Hara: ISIJ Int., 1998, vol. 38, pp. 827-33.

29. S. Yokoya, S. Takagi, M. Iguchi, K. Marukawa, and S. Hara: ISIJ Int., 2000, vol. 40, pp. 578-83.

30. Y. Tsukaguchi, O. Nakamura, P. Jönsson, S. Yokoya, T. Tanaka, and S. Hara: ISIJ Int., 2007, vol. 47, pp. 1436-43.

31. Y. Tsukaguchi, H. Hayashi, H. Kurimoto, S. Yokoya, K. Marukawa, and T. Tanaka: ISIJ Int., 2010, vol. 50, pp. 721-29.

32. Y. Yang, P.G. Jönsson, M. Ersson, and K. Nakajima: Steel Res. Int., 2015, vol. 86, pp. 341-60.

33. Y. Yang, P.G. Jönsson, M. Ersson, Z. Su, J. He, and K. Nakajima: Steel Res. Int., 2015, vol. 86, pp. 1312-27.

34. P. Ni, L. Jonsson, M. Ersson, and P. Jönsson: Steel Res. Int., 2016, vol. 87 , pp. $1356-65$.

35. H. Sun and J. Zhang: Metall. Mater. Trans. B, 2014, vol. 45B, pp. 936- 46.

36. H. Liu, M. Xu, S. Qiu, and H. Zhang: Metall. Mater. Trans. B, 2012, vol. 43B, pp. 1657-75.

37. B. Wang, W. Chen, Y. Chen, and Y. Feng: Ironmak. Steelmak., 2015, vol. 42, pp. 63-69.

38. L.B. Trindade, J.E.A. Nadalon, A.C. Contini, and R.C. Barroso: Steel Res. Int., 2017, vol. 88, Article No. 1600319

39. Q. Hou, Q. Yue, H. Wang, Z. Zou, and A. Yu: ISIJ Int., 2008, vol. 48 , pp. 787-92.

40. L. Tian and G. Ahmadi: Aerosol Sci., 2007, vol. 38, pp. 377-97.

41. H. Bai, M. Ersson, and P.G. Jönsson: ISIJ Int., 2016, vol. 56, pp. 1404-12.

42. P. Ni, D. Wang, L.T.I. Jonsson, M. Ersson, T. Zhang, and P.G. Jönsson: Metall. Mater. Trans. B, 2017, vol. 48B, pp. 2695-2706.

43. B.E. Launder, G.J. Reece, and W. Rodi: J. Fluid Mech., 1975, vol. 68 , pp. $537-66$.

44. F.S. Lien and M.A. Leschziner: Comput. Fluids, 1994, vol. 23, pp. $983-1004$.

45. ANSYS Fluent Theory Guide: Release, 2016, vol. 17, p. 85. 
46. D.C. Wilcox: Turbulence Modeling for $C F D$, DCW Industries Inc, La Canada, CA, 1998.

47. G.V. Samsonov, C.N. Turton, and T.I. Turton: The Oxide Handbook, IFI/Plenum, New York, NY, 1973.

48. A. Li and G. Ahmadi: Aerosol Sci. Technol., 1992, vol. 16, pp. 209-26.

49. P.G. Saffman: J. Fluid Mech., 1965, vol. 22, pp. 385-400.

50. S.A. Morsi and A.J. Alexander: J. Fluid Mech., 1972, vol. 55, pp. 193-208.

51. A. Haider and O. Levenspiel: Powder Technol., 1989, vol. 58, pp. $63-70$

52. A.D. Gosman and E. Ioannides: J. Energy, 1983, vol. 7, pp. 482-90.

53. D.I. Graham: Int. J. Multiphase Flow, 1998, vol. 24, pp. 335-45.
54. V. Seshadri, C.A. Silva, I.A. Silva, and E.S.A. Júnior: Technol. Metall. Mater. Miner., 2012, vol. 9, pp. 22-29.

55. M.A.G. Timmer, J.P. Oosterhuis, S. Buhler, D. Wilcox, and T.H. Meer: J. Acoust. Soc. Am., 2016, vol. 139, pp. 193-203.

56. P. Ni, L. Jonsson, M. Ersson, and P. Jönsson: Int. J. Heat Fluid Flow, 2016, vol. 62, pp. 166-73.

57. L. Zheng, A. Malfliet, P. Wollants, B. Blanpain, and M. Guo: ISIJ Int., 2016, vol. 56, pp. 926-35.

58. C.T. Crowe, J.D. Schwarzkopf, M. Sommerfeld, and Y. Tsuji: Multiphase Flows with Droplets and Particles, 2nd ed., CRC Press, Taylor \& Francis Group, Boca Raton, FL, 2012.

59. F. Zonta, C. Marchioli, and A. Soldati: Int. J. Multiphase Flow, 2013, vol. 56, pp. 172-83. 